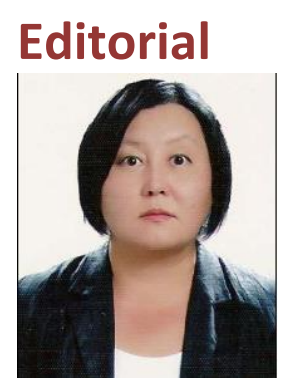

\title{
From Editor-in-Chief: Has everything changed during pandemic: peer-review, science, clinical practices and education, CV diseases?
}

Dear readers,

One of our esteemed reviewers mentioned: "Pandemics has changed everything".

When preparing editorial for this issue we wanted to share the experience with peer-review of articles during pandemics, how it has impacted our policies and also we hoped that major steps against pandemics would be taken and we will be writing more on our usual topics in scope of the journal aim. However, according to forecasting report, the pandemic is projected to be defeated only in 2 years. Therefore, we are going not only reflect the changes in journal's work and its policies in frame of pandemics, but briefly update where we are now from evidence-based point of view in war against pandemics, long-term effects of the COVID19 on cardiovascular system and how it impacted our professional life as specialists, and medical education as well.

As many journals acknowledged, there is an increase in number of submissions regardless of hot topic papers on COVID-19 $(1,2)$. However, the peer-review process underwent changes as many of authors and reviewers work on frontlines, and evidence emerges daily, leading to change in editorial evaluation $(3,4)$. Almost all articles on COVID-19 are freely accessible on websites of journals, publishers and professional societies, so many can freely read and discuss the results on many platforms. It is an unprecedented scientific crowdsourcing, which actually helps better understanding, evaluating current knowledge (retracted manuscripts) and define directions what should be done next. There may be a place for speculation that multidisciplinary crowdsourcing and approach in care also helped to prevent many deaths.

We as journal have prolonged duration of review by editors, referees and revision by authors, who work on frontline of pandemics. We are grateful to all our reviewers and editors for their excellent reviews and authors for revisions of manuscripts they made during this busy and difficult time. As Editors, we are committed to prompt evaluation of articles on emergent topic as COVID-19.

In this time of pandemics, Editors also made call to the politicians for change in policies and commitment to solve healthcare inequalities, improve public health, global health and medical research support (5), which deserves applaud and should be addressed in many countries as well.

So far, according to current evidence, in fight against COVID-19 we have in armamentarium remdesevir (6) and dexamethasone for patients on oxygen support and mechanical ventilation (7). There are negative results for tocilizumab (8), however the observational study revealed $36 \%$ reduction in mortality outcomes for patients with increased inflammatory markers generating now hypothesis to be tested in RCT (9). There are ongoing debates on use of convalescent plasma for patients with COVID-19 (10), and progress has been done for respiratory care, and multiorgan failure support, there is now an emerging knowledge on vaccines.

Address for Correspondence: Gulmira Kudaiberdieva, Heart, Vessels and Transplantation, Email: editor@hvt-journal.com

Received: 10.06.2020 Accepted: 11.06.2020

Copyright @2020 Heart, Vessels and Transplantation

doi: 10.24969/hvt.2020.215 
More evidence is available now on extrapulmonary organ involvement in COVID-19 infection (11) thromboembolism and endothelial involvement (12). Recent meta-analysis has shown the lower risk of death in hypertension patients taking angiotensin-converting enzyme inhibitor or angiotensin receptor blocker (OR $0.664, \mathrm{Cl} 0.458$ to $0.964, \mathrm{p}=0.031$ ), thd to lower risk of death in all patients with COVID-19 (13). Thus, now proving the embraced approach not to withhold the treatment with renin-angiotensin-aldosterone system inhibitors in patients with cardiovascular diseases. Recent clinical studies have shown that myocardial injury is encounted more often than it was thought and about $40 \%$ of patients with COVID-19, not only critically ill, had increased troponine values (14). Cardiac magnetic resonance studies demonstrated that $78 \%$ of patients after recovery from COVID-19 had signs of inflammation and myocardial oedema (15) or develop asymptomatic myopericarditis late after disease (16). Autopsy studies showed presence of virus genome in myocardium (17). This raises the question: Should we as cardiovascular specialists change our approach to patients recovered from COVID-19? Should we design new studies for long-term cardiovascular follow-up after recovery, or in parallel routinely assess these patients after recovery for cardiovascular involvement, and intervene if necessary?

Pandemics also affected our professional congresses, now we meet online to discuss latest news and advancements in evidence-based medicine. The ESC congress just finished (18), it was very successful offering advantage of free access to many physicians worldwide. The guidelines on atrial fibrillation, sports medicine, acute coronary syndrome and congenital heart disease were well introduced and discussed.

Pandemics has strained healthcare resources, at the peak of the curve, we experienced shortcomings in specialists of certain specialties like anesthesiology, reanimation and critical care medicine, infectious and pulmonary diseases, nurses, as many were working in shifts. As we know from communication between physicians first, at the beginning there were unprecedented examples when heart surgeons went to work in ICU as anesthesiologists, critical care specialists or even nurses to help, also residents in training and students were broadly involved in many countries. Professional societies later in time, developed also guidelines on restructuring the surgical or coronary care unit to ICUs for COVID patients.

However, the problem has risen also for the healthcare and postgraduate education policies now, when it was realized that number of specialists is not sufficient to fight pandemics, and it has led to discussion on recruitment more trainees in these specialties and shorten their residency education time to be ready for new outbreaks. The number of specialists can be increased for certain, however not in expense of their training, which usually requires minimum 4-5 years for anesthesiology training $(19,20)$ or additional 2 years of subspecialty training after training in pulmonary diseases or internal medicine (21). The material support as raise in salaries should also be considered for physicians, nurses and healthcare workers.

Concluding we should have optimistic perspective and view, as the enormous solidarity, crowd-sourcing and progress has been shown so far in producing evidence and improving clinical care of patients during pandemics and as our knowledge grows every day we feel stronger in defeating COVID-19 and return to usual care now.

We honor the lives of physicians, nurses, healthcare workers, residents and students, and all responders who lost their lives in fight against pandemics.

We wholeheartedly welcome our new Editor Prof. Nurlan Brimkulov and look forward for our cooperation in the fileds of pulmonology, high-altitude physiology and family medicine.

Follow us also on social media:

Facebook: heartvesstransplant and twitter: @heartvesstransplant

Gulmira Kudaiberdieva Editor-in-Chief Heart, Vessels and Transplantation

Peer-review: Internal Conflict of interest: None to declare Authorship: GK Acknowledgement and funding: None to declare 


\section{References}

1.Bauchner H, Fontanarosa PB, Golub RM. Editorial evaluation and peer review during a pandemic how journals maintain standards. JAMA 2020; 324: doi:10.1001/jama.2020.11764

2.Kondziolka D, Couldwell WT, Rutka JT. Putting pen to paper during a pandemic: increased manuscript submissions to the JNS Publishing Group. J Neurosurg 2020; doi: 10.3171/2020.7.JNS202691

3.Eisen MB, Akhmanova A, Behens TE, Weigel D. Publishing in the time of COVID-19. Eisen et al. eLife 2020;9:e57162;

4.Ahima RS, Jackson S, Casadevall A, Semenza GL, Tomaselli G, Collins KL, et al. Changing the editorial process at $\mathrm{JCl}$ and $\mathrm{JCl}$ Insight in response to the COVID19 pandemic. J Clin Invest 2020; 130: 2147. https://doi.org/10.1172/JCl138305

5. From Editors of The Lancet. Trump versus Biden. Lancet 2020; 396: August 22, 2020. www.thelancet.com

6. Beigel JH, Kay MT, Dodd LE, Mehta AK, et al. for ACTT-1 study group. Remdesevir for the treatment of COVID-19 -preliminary report. New Engl J Med 2020; doi: 10.1056/NEJMoa2007764

7.RECOVERY collaborative group. Dexamethazone in hospitalized patients with COVID-19 - preliminary report. New Engl J Med 2020;doi: 10.1056/NEJMoa2021436

8. COVACTA trial. Available at: URL: www.roche.com 9.Biran N, Ip A, Ahn J, Go RC, Wang S, Mathura S, et al. Tocilizumab among patients with COVID-19 in the intensive care unit: a multicentre observational study. Lancet 2020; August 14: doi: 10.106/S26659913(20)30274-5

10. Agarwal A, Mukherjee A, Kumar G, Chatterjee $P$, Bhatnagar $\mathrm{T}$, Malhotra $\mathrm{P}$, and PLACID Trial Collaborators. Convalescent plasma in the management of moderate COVID-19 in India: An open-label parallelarm phase II multicentre randomized controlled trial (PLACID Trial). medRxiv preprint doi: 10.1101/2020.09.03.20187252.
11. Gupta A, Madhavan MV, Sehgal K, Nair N, Mahajan $S$, Sehrawat TS, et al. Extrapulmonary manifestations of COVID-19. Nature Med 2020; 26: 1017-32

12. Libby $P$, Luscher T. COVID-19 is, in the end, an endothelial disease. Eur Heart J 2020; 41: 3038-44. doi:10.1093/eurheartj/ehaa623

13. Lala A, Kipp WJ, Januzzi J, Russak AJ, Paranjpe I, Zhao Sh, et al. Prevalence and Impact of Myocardial Injury 14. Puntmann VO, Carerj ML, Wieters I, Fahim M, Arendt C, Hoffman J, et al. Outcomes of cardiovascular magnetic resonance imaging in patients recently recovered from coronavirus disease 2019 (COVID-19). JAMA Cardiol; 2020; July 27; doi: 10.1001./jamacardio.2020.3557

15. Eiros R, Barreiro-Perez M, Martin-Garcia A, Almeida J, Villacorta E, Perez-Pons A, et al. Pericarditis and myocarditis long after SARS-CoV-2 infection: a crosssectional descriptive study in health-care workers. medRxiv preprint doi: 10.1101/2020.07.12.20151316

16. Lindner D, Fitzek A, Brauninger $H$, Aleshcheva $G$, Edler C, Meissner K, etal. Association of cardiac infection with SARS-CoV-2 in confirmed COVID-19 autopsy cases. JAMA Cardiol 2020; Julky 27: 10.1001./jamacardio.2020.3551

17. Baral R, White M, Vassiliou VS. Effect of ReninAngiotensin-Aldosterone System Inhibitors in Patients with COVID-19: a Systematic Review and Meta-analysis of 28,872 Patients. Current Atherosclerosis Reports 2020; doi: 10.1007/s11883-020-00880-6

18.ESC Congress 2020. The digital experience. Available at: URL: www.escardio.org

19. American Board of Medical Specialties. Available at: URL: www.abms.org, American Board of Anesthesiology. Available at: URL: www.theaba.org

20. European Training requirement ETR in Anesthesiology. Available at: URL: www.uems.eu 21. American College of Physicians. Available at: URL: www.acponline.org 
Heart, Vessels and Transplantation 2020; 4: doi: 10.24969/hvt.2020.215

On our practices

Kudaiberdieva

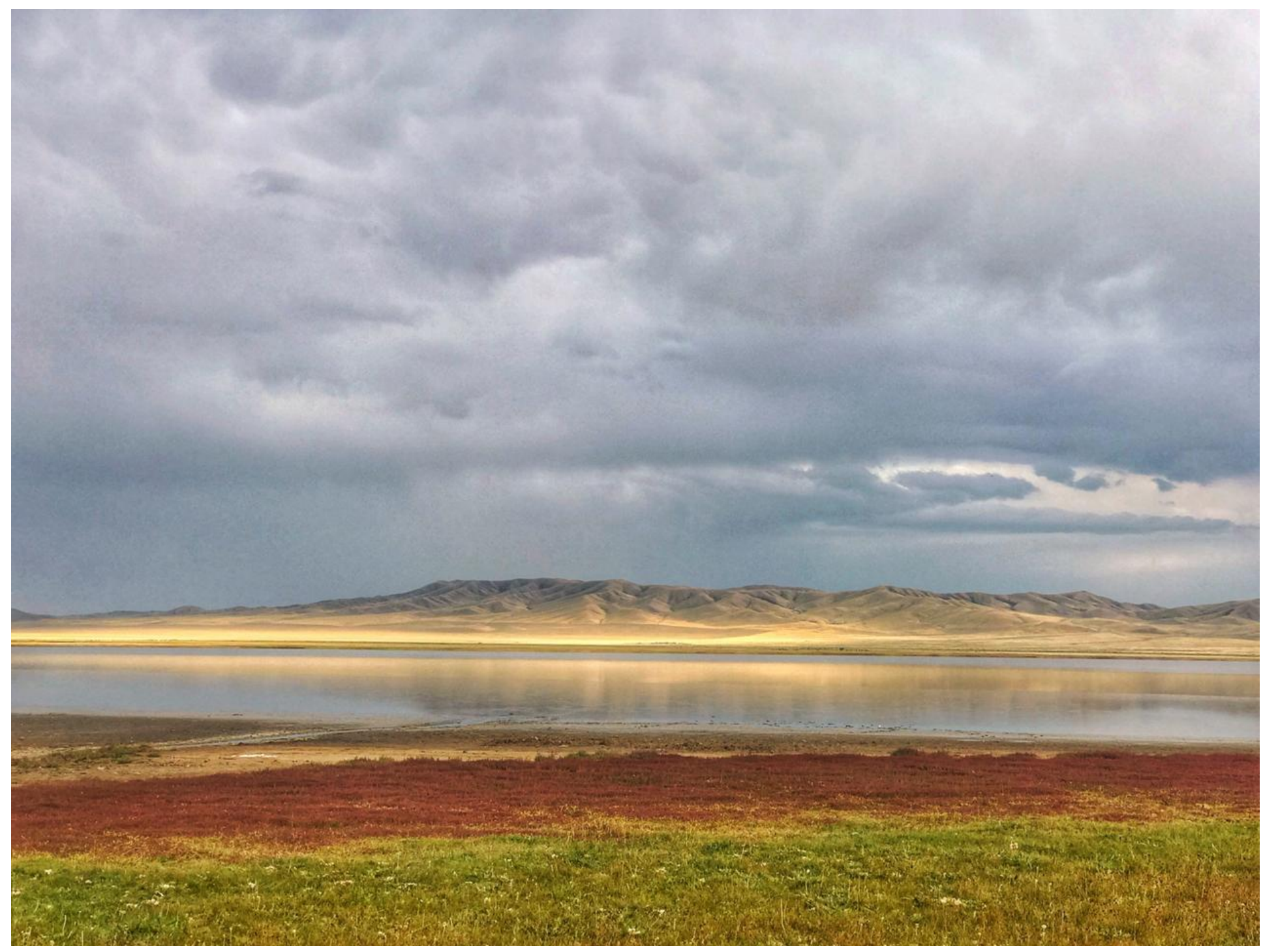

Saline lake Tuzkol, Almaty region, Kazakhstan, August 2020. Dina Dyusupova, Aktobe, Kazakhstan 